\title{
Gift-exchange Game Theory for Gamification on Digital Data Collection Systems
}

\author{
Supriyanto $^{\mathrm{a} 1}$, Jefree Fahana ${ }^{\mathrm{a} 2}$ \\ ${ }^{a}$ Informatics Department, Universitas Ahmad Dahlan \\ Yogyakarta, Indonesia \\ 1'supriyanto@tif.uad.ac.id (Corresponding author) \\ 2jefree.fahana@tif.uad.ac.id
}

\begin{abstract}
Gamification is widely used to increase user motivation by applying game elements to a digital data collection system. The use of gamification can increase user involvement so that it has an impact on the quality and quantity of data obtained. But the application of gamification is not enough, because the use of game elements requires the right strategy to increase user interaction in the system. Game theory is a solution that needs to be considered to find optimal user interaction. This paper discusses the use of game theory to find the right gamification model in digital data collection using Gift-Exchange Game Theory (GEG). Game Theory is used to find user interaction models in the gamification system. GEG-Gamification implementation is compared to gamification implementation without Game Theory. The results obtained indicate a significant increase in user involvement in the implementation of gamification with GEG. These results raise the opinion that the need to use game theory in gamification to improve user interaction on the system.
\end{abstract}

Keywords: gamification, game theory, data collection, gift exchange

\section{Introduction}

One of the purposes of information systems is to collect data. The collected data can be used for management, determining development strategies, marketing strategies, and other systems that use data scientists. In recent years the popularity of the data scientist has increased rapidly. But not for all areas, a simple example is on ecotourism. The application of technology for ecotourism cannot produce decent data to be analyzed. This causes some ecotourism is not increased even go bankrupt. Various ways to improve the development strategy and sales so that it becomes a well-developed business. But the data to be analyzed is incomplete and even not available.

This paper uses one of the ecotourism in Gunungkidul, Yogyakarta, Indonesia, for a case study. Ecotourism is used as a case study is Nglanggeran Ancient Volcano (GAP). GAP has been operating since 2011 until now. Quite a lot of information technology is used for management such as websites, online reservation systems, and e-tickets. But based on the data on the server, there are fewer than three hundred data. Small enough quantities for a system that has been running for more than five years. The problem is not the quality of information technology applied.

The problem is not only the quality of the technology used, but there are other factors. One factor to consider is the involvement of visitors in the system. Visitor involvement is the key to the success of tourism in terms of the economy [1]. In Human-Computer Interaction, user involvement is very important as one indicator of the system usability. The motivation of users to use and engage in the system needs to be improved. Gamification [2] is an effective approach to increase motivation [3][4]. Gamification is applying game elements [5] in a non-game system. The game elements that are applied include rewards, leaderboards, and badges.

Gamification has been used to improve the quality of learning and training[6][7]. Participants are motivated by giving rewards and badges for each question they complete. Gamification has also been used in positive treatment campaigns [8]. Another example of gamification in the health 
sector is Nike + application for sports activities [9]. Users get badges for certain distances that have been passed. Users can also compare the usage of other users in the community leaderboard. The application of gamification in the tourism [10] sector also provides several advantages: simplifying promotion, increasing manager productivity, increasing user loyalty, and providing education [11].

Gamification cannot be directly applied in a data collection system. In the framework of the design of the gamification system, there are steps to determine the activity loop[5]. Activity loops are determined based on the business objectives of the players. Any activity that is necessary to achieve the business objectives. Gamification could not determine if the user is really involved, doing activities as designed by management. The application of gamification needs to consider the use of game theory.

Game theory has been applied as an analysis for decision support systems in the economy [12]. The application of game theory can produce an analysis to determine policies according to market behavior. Game Theory is also used to analyze and model the Systems-of-Systems Engineering (SoSE) mechanism as a framework [13]. Game theory can be applied to SoSE in large scale applications but usually requires simulation techniques. The definition of the player and type of game depends on the engineering stage. Game Theory can be applied almost at all stages of the SoSE, especially acquisitions, designs, and operations.

Game Theory is even applied to the mechanism of selection and retrieval of information in the data warehouse [14]. The player-defined is the query process and operational costs. The goal is to produce a framework to maximize operational costs when the process of displaying information from a data warehouse. Application of Game Theory can also be found in the optimization of algorithms to detect false data and improve service quality on wireless sensor networks (WSNs) [15]. The case study used is to increase the temperature of the data collected.

Game theory with the Static Prisoners' dilemma model, Static zero-sum, Stackelberg is also used to solve problems in security and privacy issues [16]. The solution is obtained by finding equilibrium according to the features. Game theory has been used in crowdsourcing and the peer review system [17]. The application of game theory to the peer review system was quite successful in increasing motivation and efficiency in the review process.

Game theory ensures any activity or action that is done or not done by the user in the system. This paper discusses the design of gamification models with the application of game theory to increase visitor motivation to be involved in digital data collection systems. The output of the implementation of game theory is a model of interaction between the players (users) involved. This interaction model is generated to produce game elements that will be implemented in the system.

\section{Research Methods}

\subsection{Theory of Game}

The use of game theory aims to optimize solutions in the context of conflict [18]. Managers want visitors to share the content of their travel stories, while visitors feel they don't need to share. The question is what the manager must do and to achieve his goals. There are several important elements in game theory:

a. Players - entities that act as decision-makers.

b. Strategy - the player's plan to act based on previous knowledge or action.

c. Payoff - the thing the player gets after acting. The payoff can also be influenced by the actions of other players.

d. Outcome - the result of the whole game.

e. Equilibrium - the most stable outcome is the most favorable outcome for the players. It is clear that the main goal is to determine the equilibrium of all players.

The basic concept of game taken from the economic activities of sellers and buyers. But the basic concept of this game is not quite relevant to the activity in the data collection system. The activities of the digital data collection system are more relevant to employee and employer 
activities. This activity is modeled by gift-exchange-game (GEG) [19]. GEG has become standard for labor relations modeling. GEG models the employer and employee [20] as a player, as shown in Figure 1. Employers offer jobs with a certain wage value as an initial action game. The action of the employee is to accept the job offered or not at all. GEG does not have equilibrium because the worst possible outcome is that no player is harmed. The number of wages given may have an effect on the results. The higher the wages offered, the more people will accept jobs so that both will get the maximum payoff.

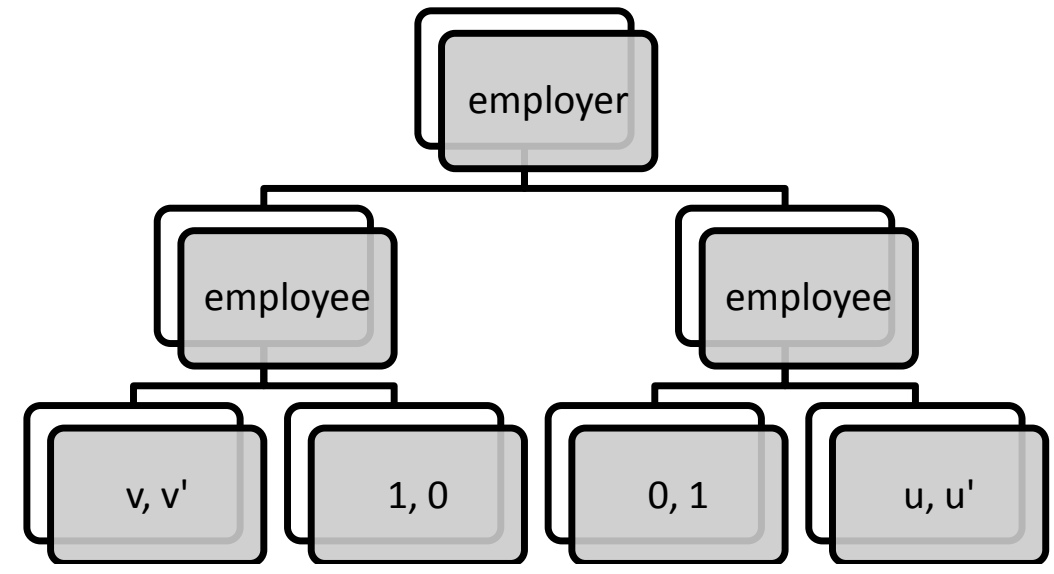

Figure 1. The Gift-Exchange-Game Scheme

\subsection{Gamification Design}

The design of the gamification model uses the D6 framework. This framework has six stages [21][22].

\section{a. Define Business Objectives}

The first most important step is to determine the objectives of gamification. The objective is to increase the involvement of visitors or tourists in the process of collecting data. The data collection discussed is data collection on ecotourism activities by utilizing information technology and social media. The involvement of the end is crucial to the success of the digital data collection process. The increasing number of visitors involved, the more data collected.

\section{b. Delineate Target Behaviours}

The second stage is designing behavioral targets to be achieved in the gamification system. Targeted behavior includes the behavior of the actors involved in the game. First is the behavior of visitors who voluntarily post their travel experience to social media and are connected to the manager's system. The second is the manager's behavior that gives intensive visitors involved. Managers must be able to determine the right intensive giving strategy.

\section{c. Describe Player}

The third stage is to describe the player. Players in the digital data collection gamification system are Managers and Visitors. This is in line with GEG's explanation, which states that there are two players, namely employer, and employee. Managers are interpreted as employers, while Visitors are employees.

\section{d. Devise Activity Loops}

The fourth stage is devising the activity loop by considering the GEG theoretical model. The GEG scheme in gamification is shown in Figure 1. Figure 1 describes the activities of the players in the gamification system. The first player became the initiator by making the first step, namely offering rewards for visitors who were willing to be involved in the data collection process. Rewarding runs if the visitor as the second player takes the next step. 
The next step is to post a tour and connect with the manager by including a specific hashtag. Payoff obtained by each player is written at the far right of Figure2. The worst payoff from GEG is zero for all players.

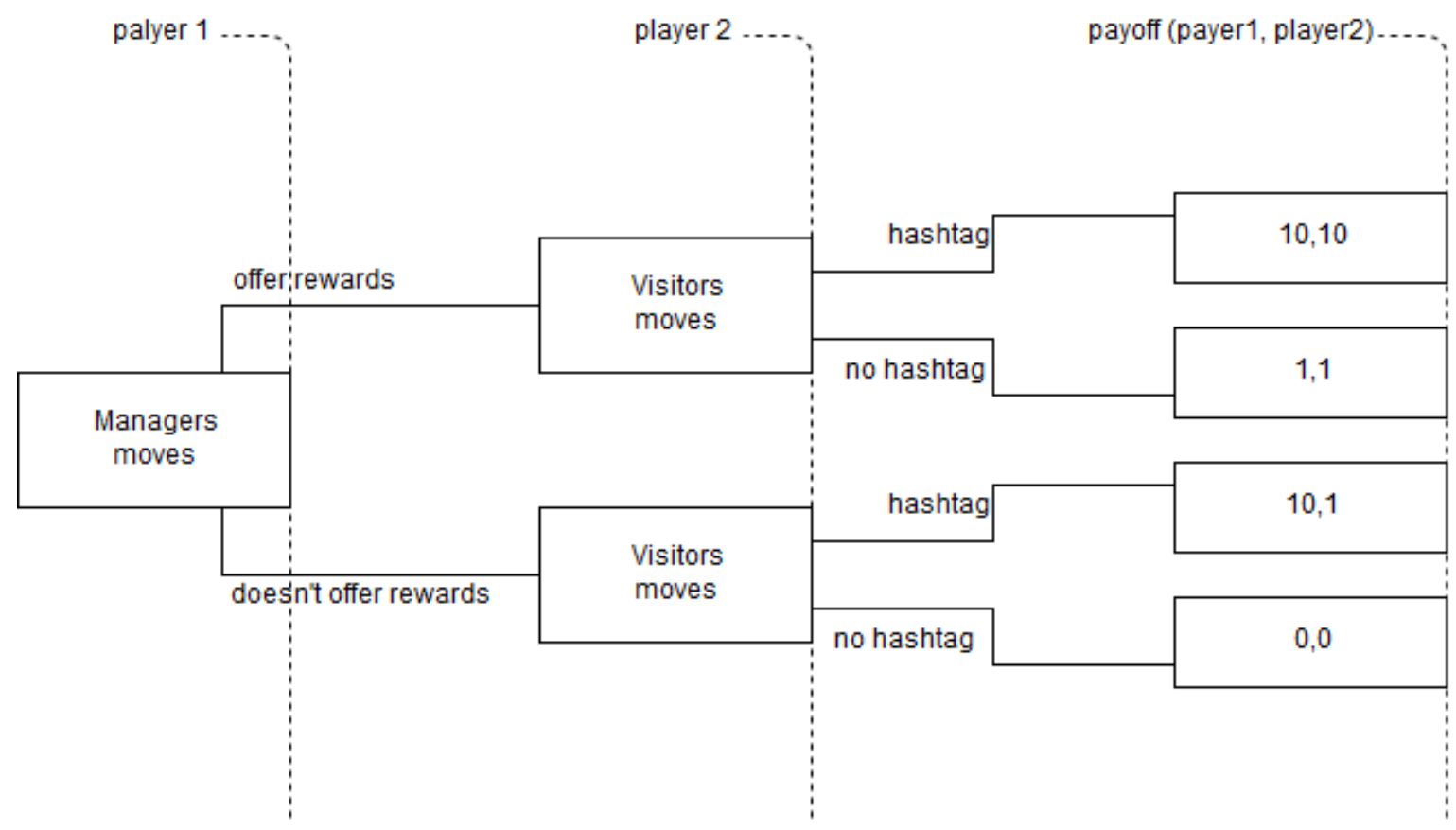

Figure 2. The Gift-Exchange-Game Implementation

\section{e. Determine Fun}

The fun element in the fifth stage is determined by how big the bid and the type of postchallenge made by the manager. Visitors only take the next step after the manager steps.

\section{f. Deploy with Appropriate Tools}

The last step is to do deployment using the right tools. Managers already have a system that has been running routinely, a web-based information system. The gamification system integrates the social media and web-based information systems of the manager. This integration will produce visitor travel story data that use the right hashtag.

\section{Result and Discussion}

The system is made based on a web site with consideration of easy access. The system architecture utilizes social media Instagram services (API), as shown in Figure 3. 


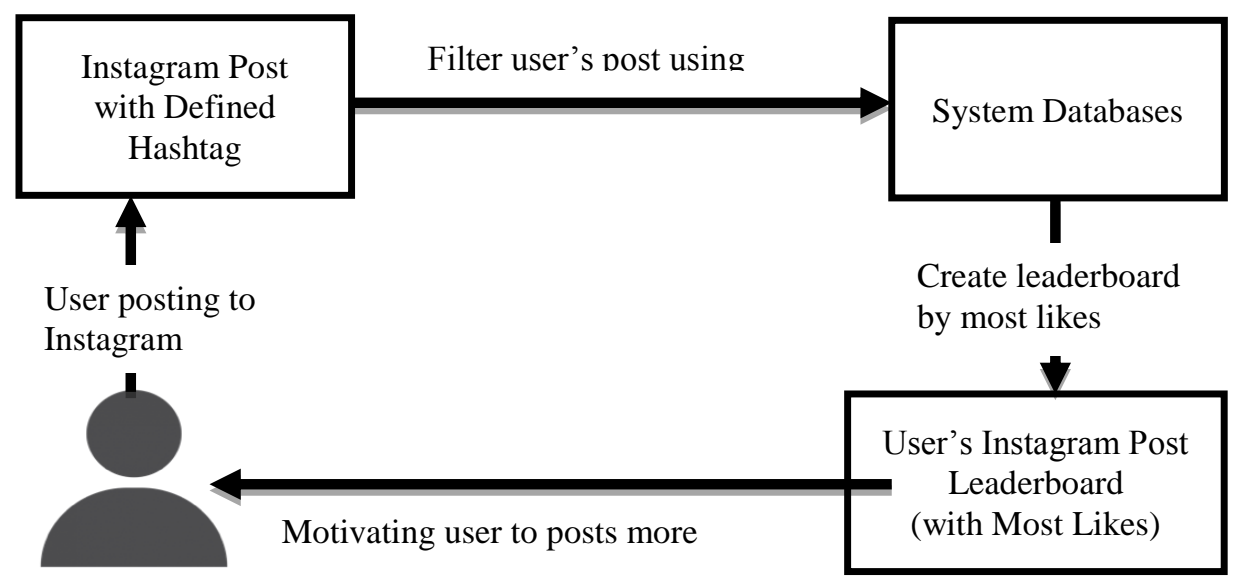

\subsection{First Experiment}

Figure 3. Gamification System Architecture

The first experiment of gamification implementation was applied to enrich the content of the web-based information system. The goal is how to retrieve data from visitors' social media. Visitors are asked to enter a specific hashtag. The gamification system has not considered a game theory. Gamification only follows the basic elements of the game: leaderboard and badges. A leaderboard is made by taking posts with the most likes and comments. The leaderboard is displayed in real-time by retrieving data from Instagram via the API at certain intervals.

The first try hasn't used GEG because the manager didn't take any steps. In other words, the action occurs only in one direction from the visitor as a single player. The experimental results show an increase in user involvement in visiting web-based information systems based on the amount of Instagram content. As a result, the number of visitors to web-based information systems has increased, shown in Figure 4.

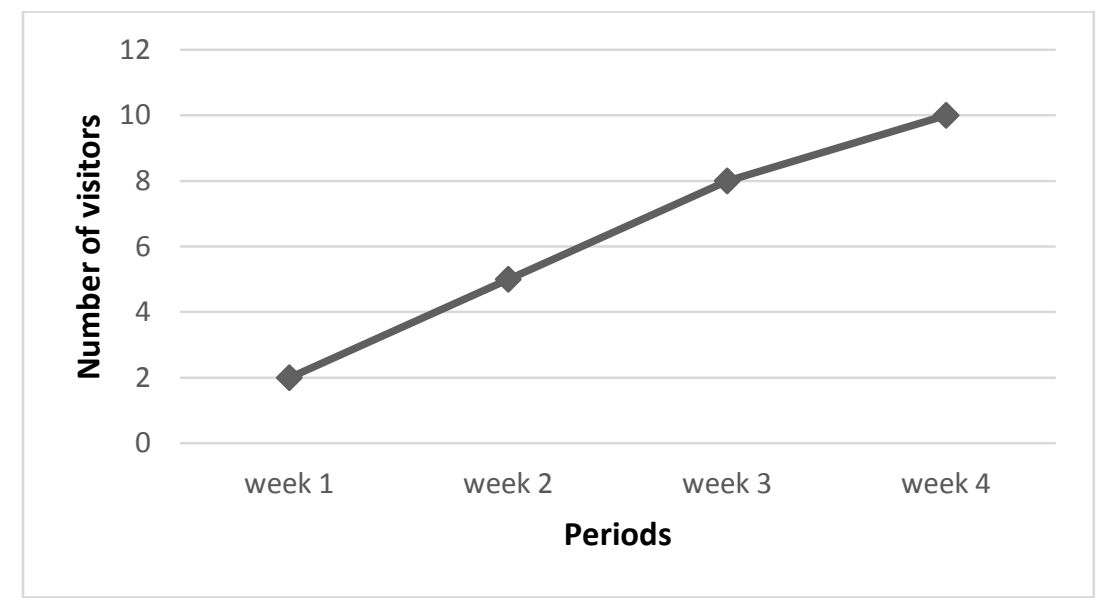

Figure 4. The result of the first experiment

\subsection{Second Experiment}

The gamification system is applied to testimonies of ecotourism product exhibitions. In this experiment, GEG has been implemented with simple game design. As Figure 5 shows, the two players (managers and visitors) have their steps. Just like the first try, visitors are asked to post photos/videos plus product testimonials. But before that, the manager did the first step by giving a gift offer. Steps taken by the manager must use the right strategy. The selection of the value/number of prizes offered with the results of the testimonial data obtained must provide 
maximum pay off. The leaderboard is no longer made using the most likes and comments data, but based on the evaluation of the judges determined by the manager.

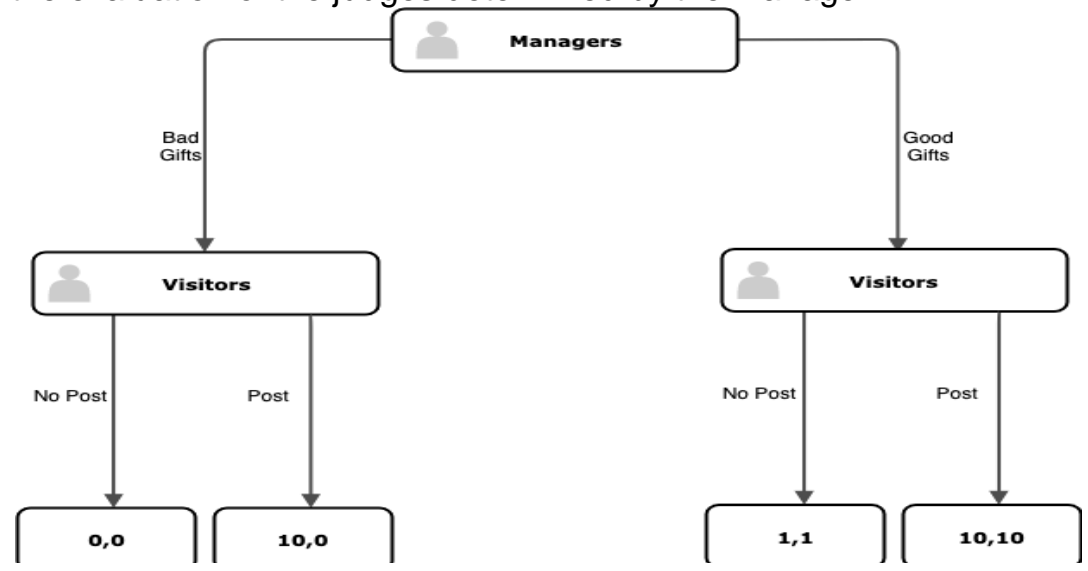

Figure 5. 2nd GEG Experiment architecture

As in the first experiment, gamification was quite successful in increasing visitor engagement in the system. But the implementation of gamification that runs does not get much data. GEG implementation is still weak because there are only two steps managers are a bad gift or good gift. So that the payoff obtained by the two players during the experiment only comes from this formula 0:0, 1:1, and 10:10. Formula 0: 0 means that both players don't get the payoff, 1: 1 means that both players get the minimum payoff and 10:10 both players get the maximum payoff. So that it can only collect less than 20 data in one month, as Figure 6 shows.

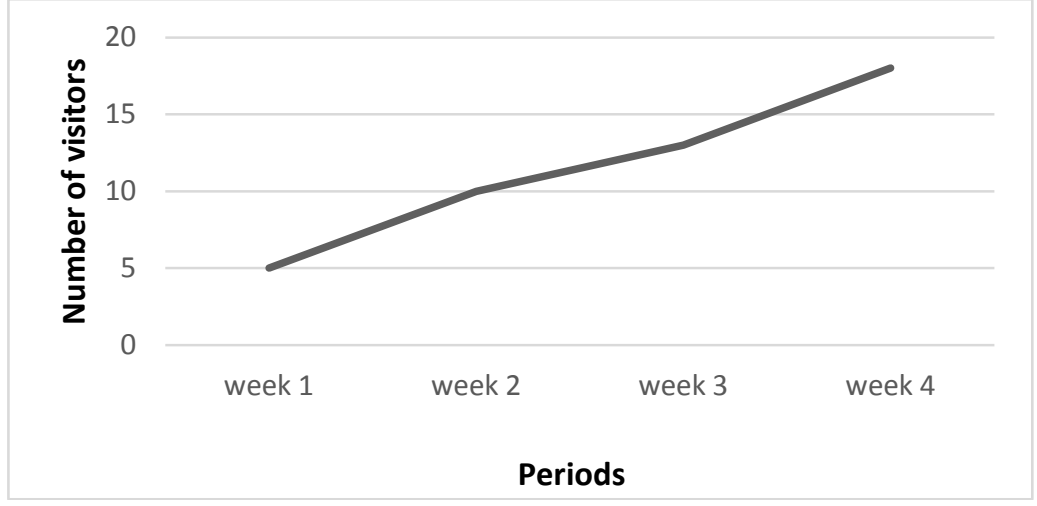

Figure 6. The result of second experiment

\subsection{Third Experiment}

The next experiment is the implementation of gamification and GEG by creating a photo competition using Instagram. The event coincided with Indonesian independence day [23]. The manager, as the first player, starts to consider the amount of reward offered. Visitors are facilitated by using Instagram badges, namely likes and comments. The design of the game starting from the first step and the existence of managers offering gifts to visitors. By default, the participants who came post the first photo to mark the participation in the event. Furthermore, visitors can take another step by increasing the number of posts. The more posts, the higher the position on the leaderboard. The design of the third experiment demonstrated payoff GEG Figure 7 change the formula payoff all significant players. 


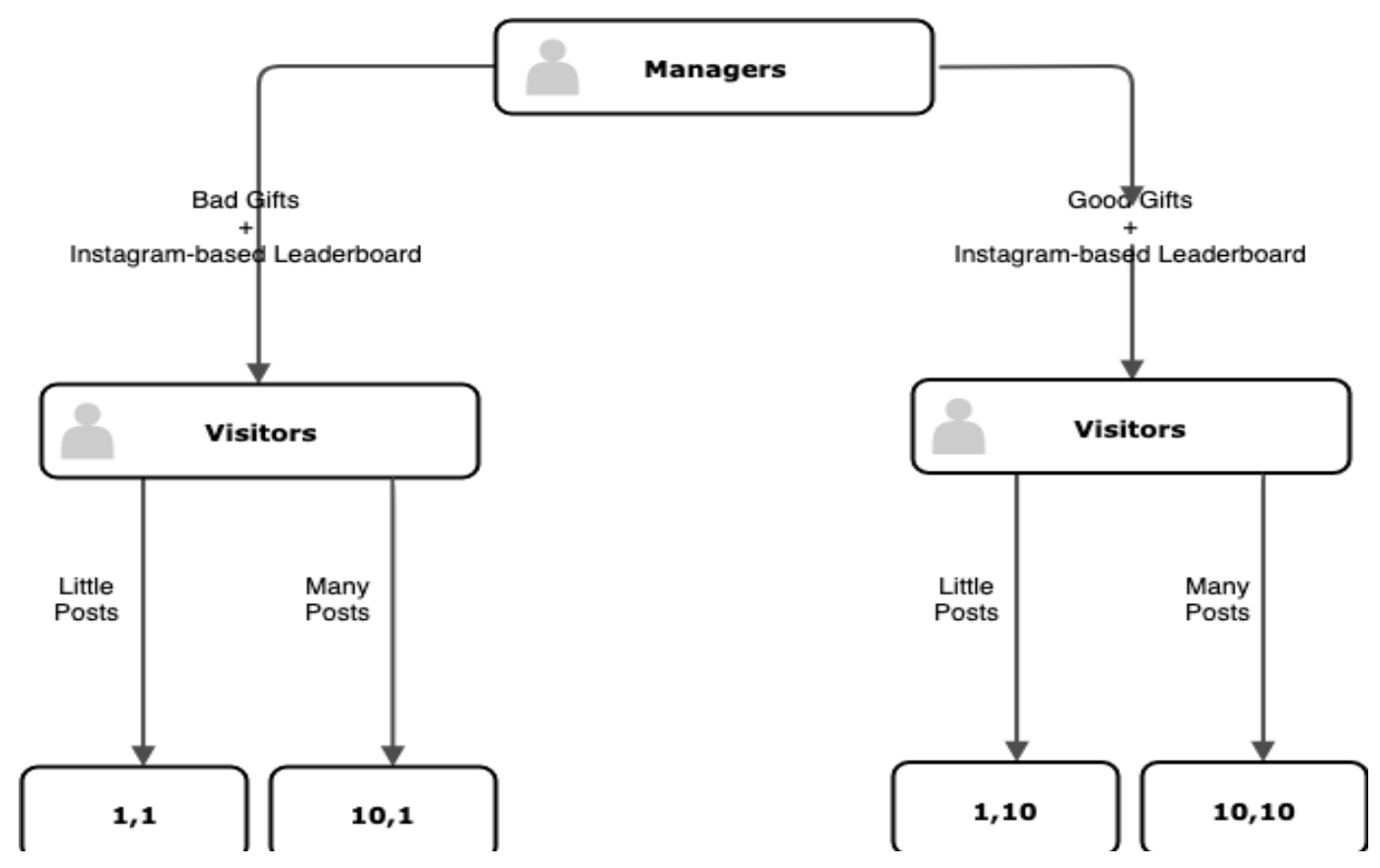

Figure 7. 3rd GEG Experiment architecture

The GEG design of this experiment allows visitors to do the post at least once. So that almost all payoff formulas can be produced, i.e., 1:1, 10:1, 1:10, and 10:10. The number of visitors who come is directly proportional to the amount of data that was successfully obtained. As a result, the number almost increased four times compared to the 1st and 2 nd experiments, as shown in Figure 8.

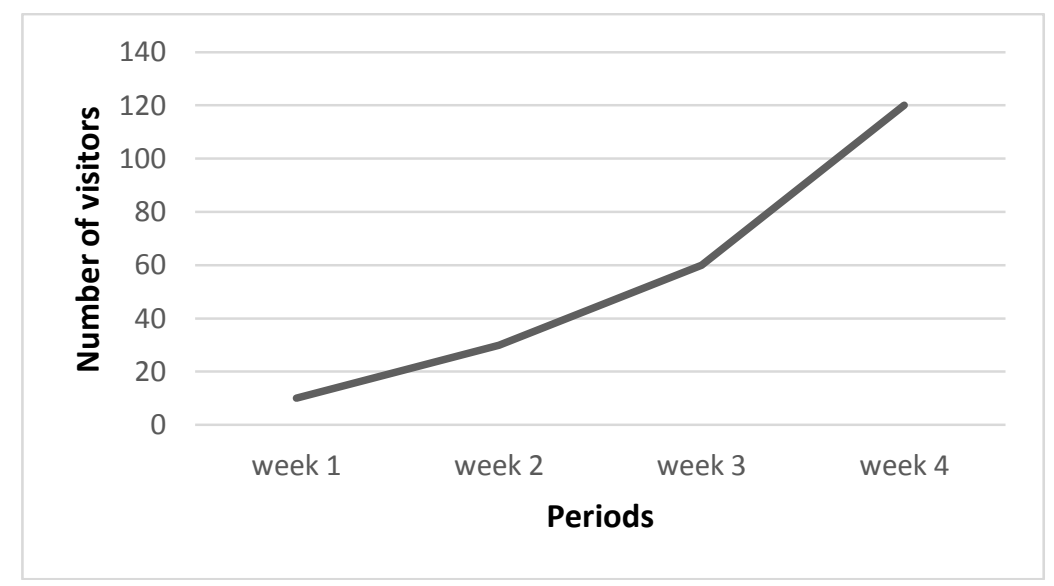

Figure 8. The result of the third experiment

\section{Conclusion}

Based on the results of the implementation in the previous section, the implementation of the three experiments did use a slightly different system but still in the same situation. From the results can be concluded that GEG is quite effective in increasing the motivation of users to be involved in digital data collection systems. But the right strategy must be considered so that the players get the maximum payoff. GEG draft, as in the first and second experiments, should be avoided. At least every player gets a payoff even though it is minimal.

The next job is how to create a digital data collection system where all user activities use their own platform. The goal is not to depend on third-party activities. In addition, consideration of 
using game theory and more challenging game designs can be used to increase visitor engagement.

\section{References}

[1] A. Negrusa et al., "Exploring Gamification Techniques and Applications for Sustainable Tourism," Sustainability Journal., vol.7, pp.11160-11189, 2015.

[2] D. Basten, "Gamification," IEEE Software., vol. 34, no. 5, pp. 76-81, 2017.

[3] S. Deterding and D. Dixon, "Gamification: Using Game Design Elements in Non-Gaming Contexts," in CHI 2011: Conference on Human Factors in Computing Systems, pp. 5-8, 2011.

[4] J. Frith, "Turning life into a game: Foursquare, gamification, and personal mobility," Mobile Media \& Communications., vol. 1, no. 2, pp. 248-262, 2013.

[5] K. Werbach and D. Hunter, For The Win: How Game Thinking Can Revolutionize Your Business. Philadelphia: Wharton Digital Press, 2012.

[6] Y. Allsop and J. Jessel, "Teachers' Experience and Reflections on Game-Based Learning in the Primary Classroom," International Journal of Game-Based Learning, vol. 5, no. 1, pp. $1-17,2015$.

[7] A. P. Markopoulos, A. Fragkou, P. D. Kasidiaris, and J. P. Davim, "Gamification in engineering education and professional training," International Journal of Mechanical Engineering Education, vol.43, issue 2, pp.118-131, 2015.

[8] A. F. Maturo and V. Moretti, Digital Health and the Gamification of Life: How Apps Can Promote a Positive Medicalization. Emerald Publishing Limited, 2018.

[9] S. Nicholson, "Strategies for meaningful gamification: Concepts behind transformative play and participatory museums.," Meaningful Play 2012, no. 1999, pp. 1-16, 2012.

[10] J. Weber, "Gaming and Gamification in Tourism: 10 Ways to Make Tourism MorePlayful. Best Practice Report," Digital Tourism Think Tank, pp. 4-14, 2014.

[11] F. Xu, J. Weber, and D. Buhasil, "Gamification in Tourism," in Information and Communication Technologies in Tourism 2014, vol. 4, no. January, 2013.

[12] A. Kelly, Decision Making Using Game Theory: An Introduction for Managers. 2003.

[13] J. Axelsson, "Game theory applications in systems-of-systems engineering: A literature review and synthesis," Procedia Computer Science, vol. 153, pp. 154-165, 2019.

[14] H. Azgomi and M. K. Sohrabi, "A game theory based framework for materialized view selection in data warehouses," Engineering Applications of Artificial Intelligence, vol. 71, no. February, pp. 125-137, 2018.

[15] R. Casado-Vara, F. Prieto-Castrillo, and J. M. Corchado, "A game theory approach for cooperative control to improve data quality and false data detection in WSN," International Journal of Robust and Nonlinear Control, vol. 28, no. 16, pp. 5087-5102, 2018.

[16] C. T. Do et al., "Game theory for cyber security and privacy," ACM Computing Surveys, vol. 50, no. 2, pp. 30-37, 2017.

[17] Schapire, Robert E. and Indraneel Mukherjee. "Game theory and optimization in boosting." 2011.

[18] MYERSON, ROGER B. Game Theory: Analysis of Conflict. Cambridge, Massachusetts; London, England: Harvard University Press, 1991. Accessed Jan 1, 2020. www.jstor.org/stable/j.ctvjsf522..

[19] M. Apagodu, D. Applegate, N. J. . Sloane, and D. Zeilberger, "Analysis of the gift exchange problem," arXiv math.CO, pp. 1-14, 2017.

[20] G. Umbhauer, Game Theory and Exercises. Routledge, 2016.

[21] A. Mora, D. Riera, C. Gonzalez, and J. Arnedo-Moreno, "A Literature Review of Gamification Design Frameworks," 2015 7th International Conference on Games and Virtual Worlds for Serious Applications (VS-Games), September, pp.1-8, 2015.

[22] J. Hamari, "Framework for Designing and Evaluating Game Achievements," Proceedings of DiGRA 2011 Conference: Think Design Play, pp. 20, 2011.

[23] Supriyanto, J. Fahana and S. Handoko, "Gamification to Improve Digital Data Collection in Ecotourism Management," 2018 2nd East Indonesia Conference on Computer and Information Technology (EIConCIT), Makassar, Indonesia, 2018, pp. 139-142.. 